\title{
Dose Distribution Analysis of Proton Therapy for Medulloblastoma Cancer with PHITS 3.24
}

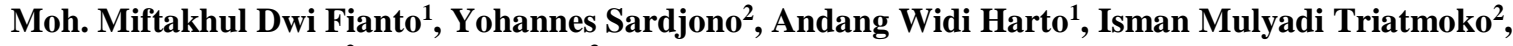 \\ Gede Sutresna Wijaya ${ }^{2}$, Yaser Kasesaz ${ }^{3}$ \\ ${ }^{I}$ Department of Nuclear Engineering and Engineering Physics, Faculty of Engineering, Universitas Gadjah Mada, Indonesia \\ ${ }^{2}$ Center for Research Technology Accelerator, Organization for Research Nuclear Energy, National of Research and Innovation Agency, Indonesia \\ ${ }^{3}$ Nuclear Scientific Data Center and Nuclear Science and Technology Research Institute, Iran
}

\section{ARTICLE INFO}

\section{Article history:}

Received: 17 January 2022

Received in revised form: 04 February 2022

Accepted: 11 February 2022

\section{Keywords:}

Proton therapy

Passive scattering

Pencil beam scanning

Posterior fossa boost

Medulloblastoma

\begin{abstract}
A B S T R A C T
One of the developments in particle therapy is proton radiation therapy. Research related to proton therapy is difficult due to a limited number of available proton therapy facilities. Therefore, there is a need for alternative proton therapy simulations using programs other than those in proton therapy facilities. This research was aimed to simulate medulloblastoma brain cancer which is most common in children. The program used in this research was PHITS version 3.24. The human body was modeled with the revised ORNL-MIRD phantom for a 10 -year-old child. The therapy scheme was a whole posterior fossa boost of $19.8 \mathrm{~Gy}$ RBE. The proton passive scattering was simulated by passing a uniform proton beam through the aperture and compensator with various energy levels. The proton pencil beam scanning was simulated with small cylindrical beams with a radius of $0.5 \mathrm{~cm}$, which were adjusted to the planning target volume with layers variations. The total duration of the prescription dose given was 550 seconds with passive scattering and 605 seconds with pencil beam scanning. In passive scattering, the OAR(s) with the most significant percentage of absorbed dose were the skin, cranium, and muscle, i.e., $8.22 \pm 0.15 \%, 5.51 \pm 0.05 \%$, and $1.39 \pm 0.04 \%$ respectively to their maximum tolerated dose. For the pencil beam scanning, the OAR(s) with the most significant percentage of absorbed dose were the skin, cranium, and muscle, i.e., $5.42 \pm 0.08 \%, 4.43 \pm 0.05$ $\%$, and $0.51 \pm 0.05 \%$ respectively to their maximum tolerated dose. In terms of dose homogeneity, dose distribution in passive scattering was relatively better than in pencil beam scanning using dose sampling analysis at some points within the planning target volume.
\end{abstract}

\section{INTRODUCTION}

After the discovery of X-ray radiation used for medical imaging of the human body by William Roentgen in 1895, ionizing radiation became an interesting topic in the medical field, especially in the field of oncology. More and more studies are being developed to determine the effects of radiation in biological tissues. Currently, the technology has been developed for the use of particle radiation. Particle radiotherapy that is being developed uses proton radiation[1]. Proton therapy is recommended to treat irregular-shape tumors located in hard-toreach areas or close to critical organs, such as brain

\footnotetext{
* Corresponding author.

E-mail: mohmiftakhuldwi99@mail.ugm.ac.id

DOI: $10.17146 / \mathrm{tdm} .2022 .24 .1 .6581$
} 
tissue. Proton therapy can deliver a large dose to tumor tissue but not to surrounding tissue because of the effect of charged particle radiation, namely Bragg Peak. In 2021, Indonesia installed a proton therapy center at Gatot Subroto Army Hospital, Jakarta, with the vendor IBA (Ion Beam Applications SA) Proteus®ONE[2].

The parts of the human body which are more sensitive to radiation are the brain and nervous system. Thus, radiotherapy for treating cancer in that area must be as conformal as possible. Therefore, proton radiotherapy is highly recommended[3]. In Indonesia, brain and central nervous system cancer in 2020 are ranked 15th of the highest number of cancers with a total of 5,964 cases and a death rate of 5,298 cases[4]. Meanwhile, the cost of treating cancer by national health insurance (BPJS Kesehatan) reaches 3.5 trillion rupiahs and ranks second after heart diseases[5].

Medulloblastoma is a malignant tumor/cancer located in the part of the brain called the cerebellum (small brain). Medulloblastoma can occur at any age, but most commonly in children. Although medulloblastoma cases are quite rare compared to all brain cancers, medulloblastoma is a common type of cancer experienced by children [6].

The use of proton therapy in clinical use is inseparable from the software called TPS (Treatment Planning System). It is used to create, evaluate, execute, and save the results of a patient's therapy plan. However, TPS used in hospitals are commercial TPS which cannot be easily accessed outside of clinical use. This condition is more significant when considering proton therapy. The limited number of proton therapy facilities makes research related to proton therapy difficult. Therefore, there is a need for alternative software to simulate proton therapy[7]. PHITS (Particle and Heavy Ion Transport Code System) is a Monte Carlo simulation application used to simulate charged particles in matter. PHITS can be used to simulate nuclear reaction processes in accelerator technology, radiotherapy, cosmic radiation, and other phenomena related to particle and heavy-ion radiation. Various institutions support PHITS until its latest version of 3.24[8].

This study is focused on the replication of treatment planning for the medulloblastoma cancer case using the PHITS version 3.24 to determine the dose distribution received by healthy organs around the planning target volume. This study is useful to provide information about proton radiotherapy simulation for whole posterior fossa boost irradiation cases using a relatively new program (PHITS version 3.24) rather than using commercial
TPS software which is accessible only inside the healthcare facility.

\section{RESEARCH METHOD}

This study is research with software simulation. The equipment used are:

1. A portable computer with specifications: Processor AMD Ryzen 3 2200U dual-core, RAM 4GB, Operating system: Windows 10 Home 64-bit.

2. Particle and Heavy Ions Transport Code System (PHITS) simulation program version 3.24, licensed by JAEA.

3. Microsoft Excel 365.

4. Microsoft Word 365.

5. Notepad++, to write and read input and output PHITS' code.

6. EPS/PS viewer, to display the PHITS' output graph.

The system reference for simulating proton therapy is the Proteus ${ }^{\circledR O N E}$ system with cyclotron S2C2 made by IBA[9].

Table 1 Proteus ${ }^{\circledR O N E}$ spesifications[9]

\begin{tabular}{|c|c|c|}
\hline No. & Parameter & Description \\
\hline 1 & Beam energy & $70-230 \mathrm{MeV}$ \\
\hline 2 & Particle & Proton \\
\hline 3 & Beam structure & $\begin{array}{l}1000 \mathrm{~Hz} \text { pulse, } 10 \mathrm{~s}, \\
6 \times 10^{8}-1 \times 10^{12} \\
\text { protons } / \mathrm{sec}\end{array}$ \\
\hline 4 & $\begin{array}{l}\text { Maximum angle } \\
\text { range of gantry }\end{array}$ & $220^{\circ}$ \\
\hline 5 & $\begin{array}{l}\text { Source distance to } \\
\text { the patient }\end{array}$ & $\begin{array}{l}0.5-32 \mathrm{~cm} \text { pencil beam } \\
\text { scanning }\end{array}$ \\
\hline 6 & Irradiation time & $\begin{array}{l}2 \text { minutes for } 2 \mathrm{~Gy} \text { and } 1 \\
\mathrm{~L} \text { volume }(10 \times 10 \times 10 \\
\mathrm{cm})\end{array}$ \\
\hline
\end{tabular}

\subsection{Literature review}

Previous studies were used as parameter references and predictions to this research results. The literature review was aimed to complete the theoretical basis and understanding related to the problems. In addition, learning how PHITS works was carried out using the available tutorials along with the PHITS distribution zip file from JAEA. Everything about PHITS was obtained through the JAEA website https://phits.jaea.go.jp/.

\subsection{Modeling the geometry of the patient's body and organs}

The geometry of the human body modeled in PHITS refers to the phantom of a 10-year-old child from ORNL-MIRD (Oak Ridge National Laboratory-Medical Internal Radiation Dose) 
modified by Young Han, Eun[10]. The material used in this phantom refers to ICRP Publication 89 and ICRU Report 46, which composition corresponds with the original code of the phantom. The phantom was modified without changing the material composition or organ size by only displaying the head to simplify the listing of the input code and reduce simulation time since the target of therapy and Organ(s) at Risk / OAR(s) were reviewed only in the head. The phantom was viewed from the sagittal cut, as shown in Figure 1.

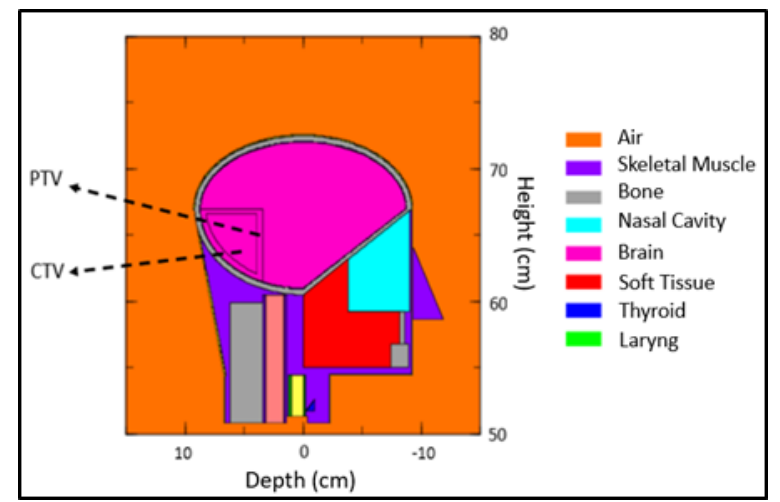

Fig. 1. Sagittal view of the head phantom model

Radiotherapy for medulloblastoma cancer modeled in this study was a whole posterior fossa boost of 19.8 Gy RBE, a continuation of CSI (Craniospinal Irradiation) therapy of $36 \mathrm{~Gy}$ RBE for high-risk cases[11-13]. The radiotherapy volume modeled were CTV (Clinical Target Volume) and PTV (Planning Target Volume) since it was assumed that all tumor volume had been surgically removed so that the entire posterior fossa area was modeled with CTV, while the PTV area was the CTV area plus a margin of 3 to $5 \mathrm{~mm}[14]$.

\subsection{Modeling proton beams}

The proton therapy was modeled with the proton beam delivery system according to the IBA Proteus One specification. Two variations of the proton beam delivery technique were used. First, is passive scattering, which was a uniform beam passing through aperture and compensator. Second, pencil beam scanning was multiple beamlets in the form of a cylinder with a radius of $0.5 \mathrm{~cm}$. Beam's parameters modeled in this simulation are shown in Table 2.

Proton radiotherapy can be done with one (single field) or more radiation fields (multiple fields)[15]. This study simulated the therapy with one irradiation field to simplify the simulation process. The direction of irradiation was from behind the phantom to the front (posterior-anterior). It was carried out this way to make the proton beam less likely to hit vital organs. In addition, the PTV area was closer to the rear area of the phantom so that other vital organs were less exposed to proton beam radiation.

Table 2. Beam parameters modeled in the simulation

\begin{tabular}{llll}
\hline No & Parameter & $\begin{array}{l}\text { Passive } \\
\text { Scattering }\end{array}$ & $\begin{array}{l}\text { Pencil } \\
\text { Beam } \\
\text { Scanning }\end{array}$ \\
\hline 1 & $\begin{array}{l}\text { Energy range } \\
(\mathrm{MeV})\end{array}$ & $70-138 \mathrm{MeV}$ & $\begin{array}{l}70-115 \\
\mathrm{MeV}\end{array}$ \\
2 & $\begin{array}{l}\text { Particle } \\
\text { Beam intensity }\end{array}$ & $\begin{array}{l}\text { Proton } \\
1 \times 10^{10}\end{array}$ & $\begin{array}{l}\text { Proton } \\
1.5 \times 10^{8}\end{array}$ \\
4 & $\begin{array}{l}\text { Beam size } \\
\text { (radius) }\end{array}$ \\
5 & $\begin{array}{l}\text { Source distance } \\
\text { to the phantom }\end{array}$ & $30 \mathrm{~cm}$ & $30 \mathrm{~cm}$ \\
6 & $\begin{array}{l}\text { Number of } \\
\text { particles in one } \\
\text { run }\end{array}$ & 100,000 & 100,000 \\
7 & $\begin{array}{l}\text { Number of } \\
\text { batches in one } \\
\text { run }\end{array}$ & 10 & 18 \\
\hline
\end{tabular}

After the geometries of the phantom and proton beam were obtained, the simulation can be continued. In the passive scanning technique, a proton beam was formed through an aperture with a large atomic number material; brass is usually used[1] with a density of $8.6 \mathrm{~g} / \mathrm{cm}^{3}$ and passed an acrylic compensator[1] with a density of $1.18 \mathrm{~g} / \mathrm{cm}^{3}$ to match the shape and depth of the PTV area. The proton beam energy was adjusted to the size of the PTV so that the SOBP (Spread Out Bragg Peak) curve would be formed covering the entire PTV.

The aperture and compensator designs were made by adjusting the irradiation target and then checking to find out whether the results of the particles' track were fit with the irradiation target or not. The aperture and compensator designs are shown in Figure 2, while the passive scattering particle's track is shown in Figure 3. 


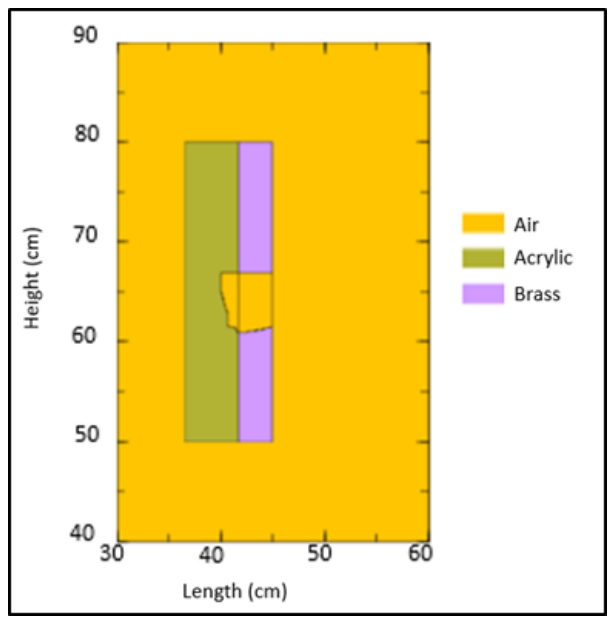

Fig. 2. Aperture and compensator design

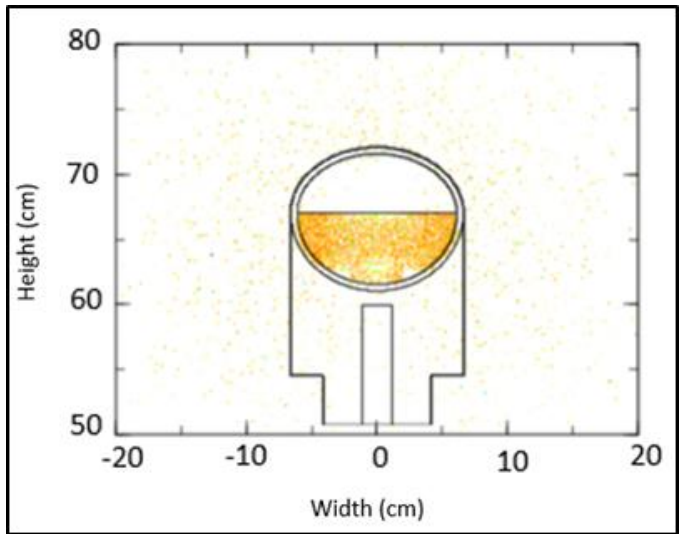

Fig. 3. Front view of proton beam passive scattering technique

\subsection{Dose distribution and fractionation}

Several points were sampled in the PTV area to analyze the dose distribution in the irradiation target. the sampling point was a sphere with a radius of 0.5 $\mathrm{cm}$. Table 3 provides the coordinates of the eight sampling points.

Table 3. Coordinate the sampling points

\begin{tabular}{lll}
\hline No & Point Name & $\begin{array}{l}\text { Coordinate } \\
(\mathrm{cm})\end{array}$ \\
\hline 1 & Point 1 (middle, up, front, & $0 ; 4 ; 66.5$ \\
& PTV) & $4 ; 5 ; 66$ \\
2 & Point 2 (left, up, PTV) & $-4 ; 5 ; 66$ \\
3 & Point 3 (right, up, PTV) & $0 ; 7.5 ; 66$ \\
4 & Point 4 (middle, rear, top PTV) & $2 ; 4 ; 64$ \\
5 & Point 5 (left, center PTV) & $-2 ; 4 ; 64$ \\
6 & Point 6 (right, middle PTV) & $0 ; 6 ; 64$ \\
7 & Point 7 (middle, bottom PTV) & $0 ; 4 ; 62.5$ \\
8 & Point 8 (middle, bottom PTV) & 0.45 \\
\hline
\end{tabular}

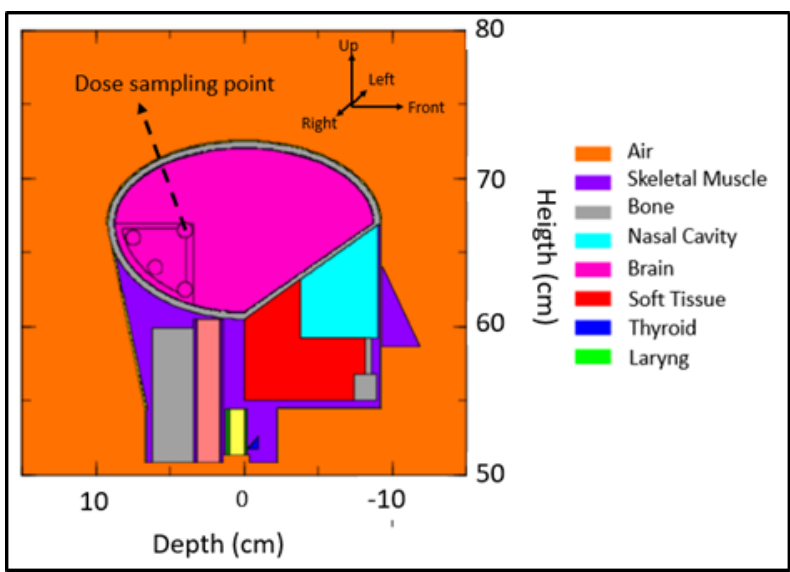

Fig. 4. Illustration of the sampling points

Calculation of the fractionation was carried out using the standard protocol to treat medulloblastoma, that is administration dose 1.8 Gy RBE (Relative Biological Effectiveness) per fraction until it reaches the planned dose of $19.8 \mathrm{~Gy}$ RBE. The calculation of the time over a fraction was carried out using Eq. 1.

$$
\text { time for one fraction }=\frac{1.8 G y R B E}{\text { dose rate }\left(\frac{G y R B E}{s}\right)}
$$

The total therapy time was obtained by multiplying the time for one fraction by the number of fractions. The number of fractions was obtained by dividing the planned dose by the dose for one fraction.

Total therapy time $=$ time for one fraction $\times$

$$
\text { number of fractions }
$$

Number of fractions $=$

$$
\frac{\text { planned dose }(19.8 \text { Gy } R B E)}{\text { dose for one fraction }(1.8 \text { Gy RBE })}=11 \text { times }
$$

\section{RESULTS AND DISCUSSION}

The SOBP curve in passive scattering was made by summing the product of each beam's energy profile depth dose with the intensity weighting factor. Fig. 5 shows the passive scattering SOBP curve with an energy variation of 74-117 MeV with $1 \mathrm{MeV}$ increments. Meanwhile, making the SOBP curve in the pencil beam scanning technique was done by summing the product of profile depth dose from each layer by the intensity weight factor. The SOBP curve of the pencil beam scanning technique is shown in Fig. 6. The value of the intensity weighting factor for the pencil beam scanning technique is different from the intensity weighting factor for the passive scattering technique.

For the SOBP curve of the passive scattering technique, when the proton beam entered the phantom, it showed a relatively high value (about 
90\%) compared to the maximum dose of SOBP. This is due to the low-profile dose (Bragg peak) of the proton beam depth at low energies. However, when compared to the accumulated total dose in Fig. 7, the absorbed dose to the skin is $1.315 \pm 0.024$ Gy RBE or only $8.22 \pm 0.15 \%$ of the skin's tolerance dose as shown in Table 4.

For the pencil beam scanning technique, the beam on the SOBP curve has an entrance curve about $80 \%$ of the maximum dose and about $10 \%$ lower than the passive scattering technique. The entrance proton beam dose compared to the total accumulated dose is shown in Figure 8. The absorbed dose to the skin is $0.868 \pm 0.012$ Gy RBE or only $5.42 \pm 0.08 \%$ of the skin's tolerance dose. This dose difference is due to the different techniques in delivering the beam. In pencil beam scanning, the proton beam was not passed through a compensator for the beam-shaping process, instead, it was adjusted directly to the PTV shape in the form of small cylinders. Both the passive scattering and pencil beam scanning techniques have a sharp distal fall-off $(\sim 1 \mathrm{~cm})$, so they did not hit the healthy part of the brain that exceeds the PTV area.

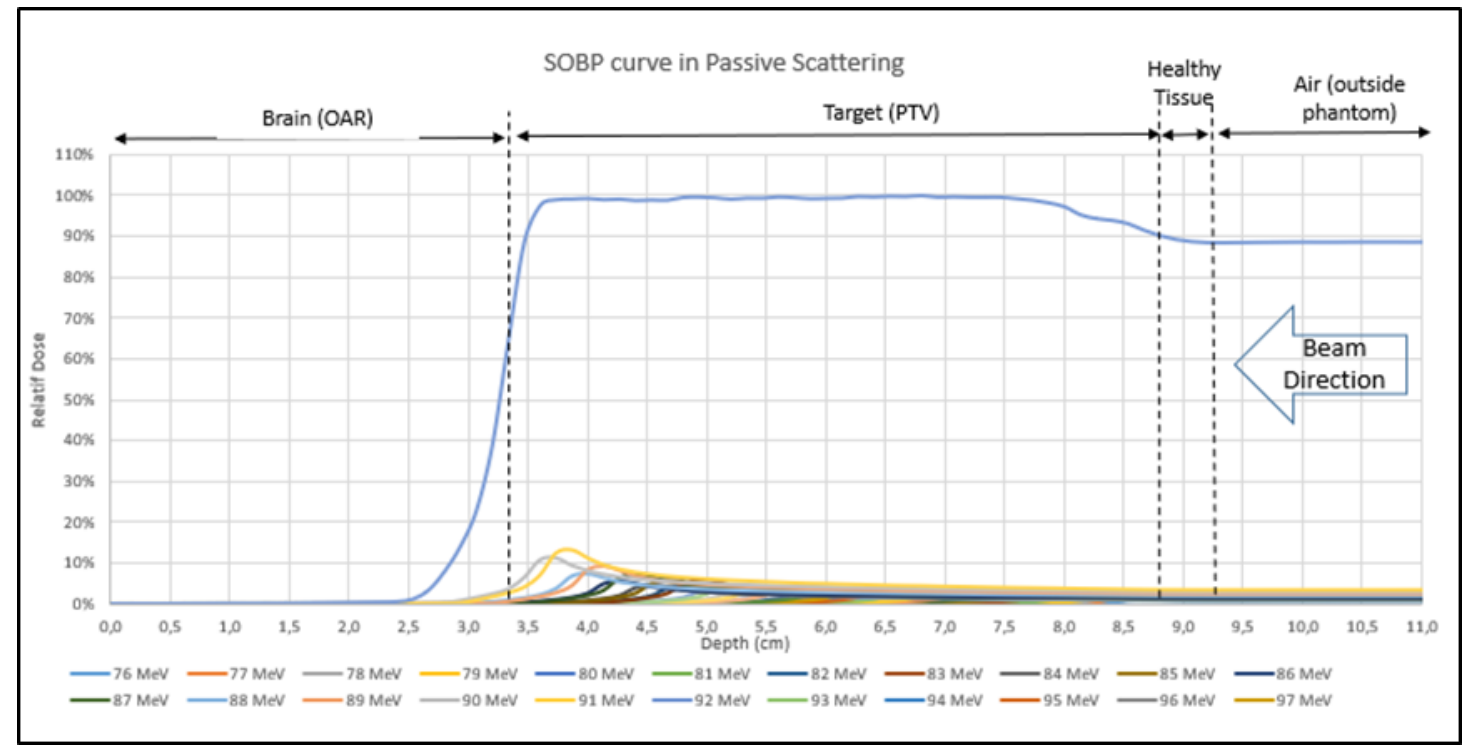

Fig. 5. SOBP curve in passive scattering

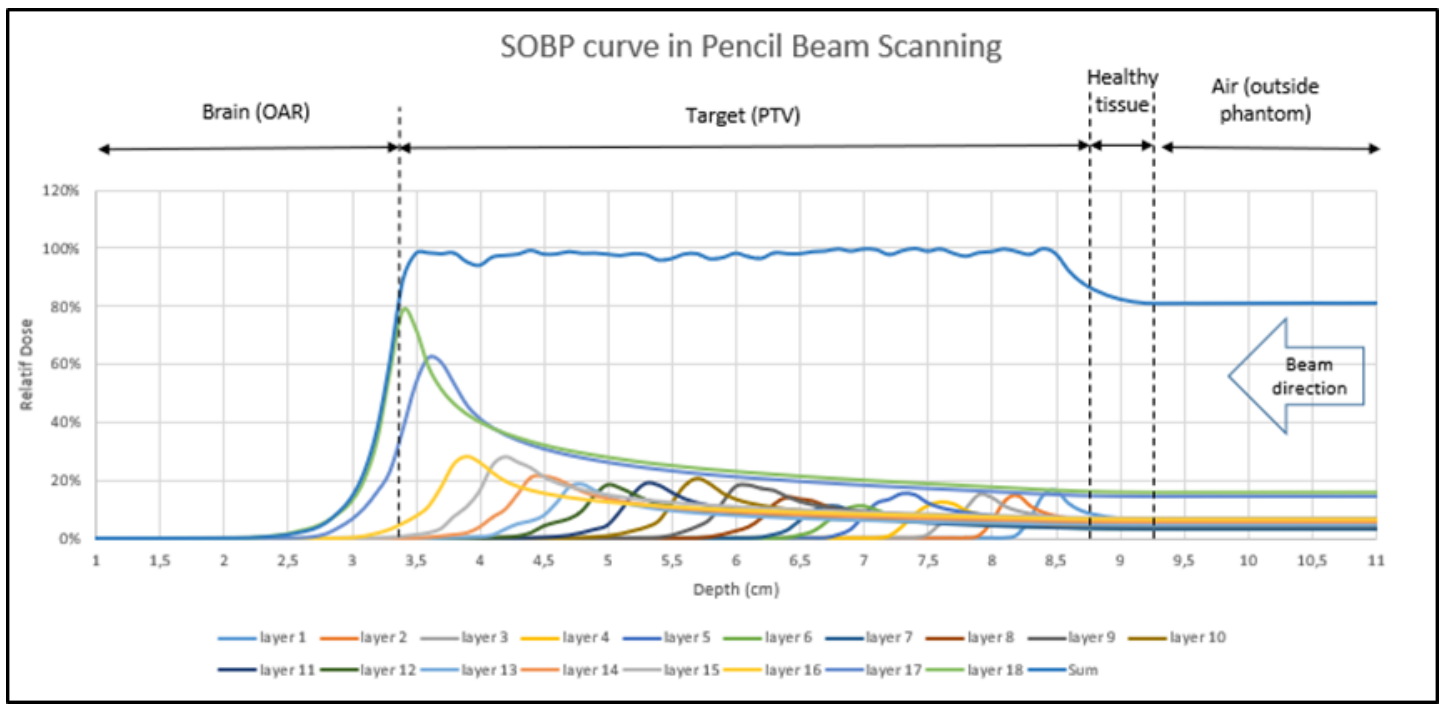

Fig. 6. SOBP curve in pencil beam scanning 
Table 4. Normal tissue tolerance dose[16-19]

\begin{tabular}{llc}
\hline No. & $\begin{array}{l}\text { Organ(s) at Risk / } \\
\text { OAR(s) }\end{array}$ & $\begin{array}{l}\text { Maximum } \\
\text { Radiation Dose } \\
\text { (Gy RBE) }\end{array}$ \\
\hline 1 & Skin & 16 \\
2 & Cranium & 52 \\
3 & Salivary gland & 24 \\
4 & Nasal cavity wall & 43.5 \\
5 & Brain & 60 \\
6 & Left eye & 6 \\
7 & Right eye & 6 \\
8 & Thyroid & 20 \\
9 & Muscle & 70 \\
10 & Spine & 50 \\
\hline
\end{tabular}

The amount of absorbed dose to the vital organs or OAR(s) with passive scattering technique after calculating the PHITS' output on Ms. Excel is shown in Figure 7. As a comparison, the pencil beam scanning technique is displayed in Figure 8. Visualization was made using a bar chart with blue bars showing the amount of absorbed dose with a vertical axis on the left, while orange bars indicate the percentage of absorbed dose compared to the tolerance dose of each organ with the vertical axis on the right side of the figure.

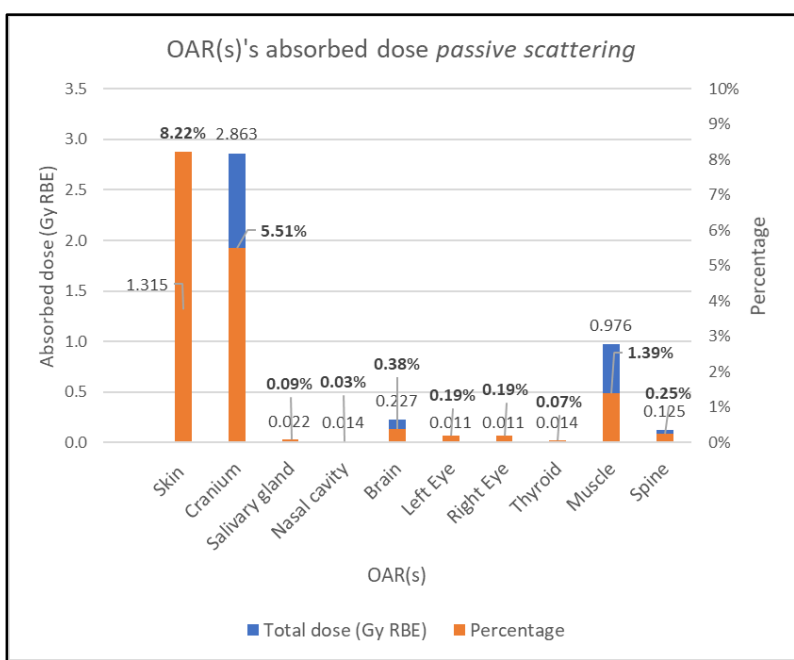

Fig. 7. OAR(s) absorbed dose for passive scattering

Figure 7 shows the distribution of the absorbed dose received by healthy organs in the form of a percentage of the maximum tolerated radiation dose that the healthy organ can receive before complications due to radiation occur.

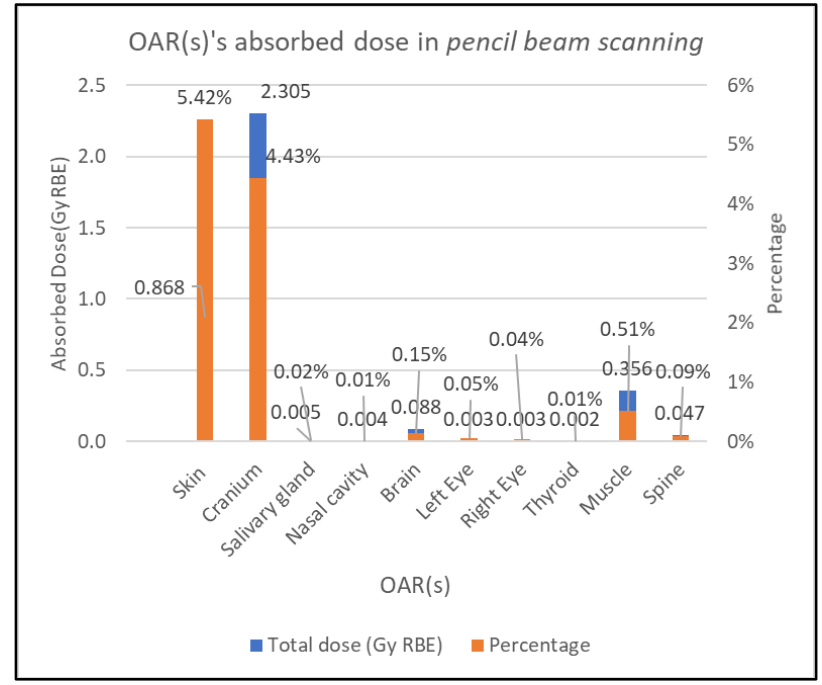

Fig. 8. OAR(s) absorbed dose for pencil beam scattering

Healthy organs with the highest radiation dose percentage compared to the tolerance dose using passive scattering technique were the skin, cranium, and muscle, i.e., $8.22 \pm 0.149 \%, 5.51 \pm 0.05 \%$, and $1.39 \pm 0.037 \%$. The reason is that the direction of the beam was only in one direction and one field. It was the PA (posterior-anterior) direction. The amount of radiation dose received by OAR(s) was still far from the maximum tolerated dose, so the use of proton therapy with passive scattering technique was still safe.

Dose distribution for healthy organs/OAR(s) using the pencil beam scanning technique can be seen in Figure 8. The largest dose percentage received were skin, cranium, and muscle, i.e., 5.42 $\pm 0.08 \%, 4.43 \pm 0.05 \%, 0.51 \pm 0.05 \%$ of the tolerance dose. There are differences in absorbed dose value by healthy organs from passive scattering and pencil beam scanning techniques. This difference occurred due to the difference in the delivery of the proton beam. In the passive scattering technique, the proton beam has an area formed through the aperture and compensator, so that the accuracy of the formation of the beam that directed on the irradiation target was not significantly high. In addition, in the passive scattering technique, the beam was passed through a compensator so that the quality of the beam was slightly reduced. While in the pencil beam scanning technique, the beam was formed from small cylinders adjusted to the irradiation target and did not use a compensator, so the beam quality became better, which resulted in a higher proton dose to the target. 


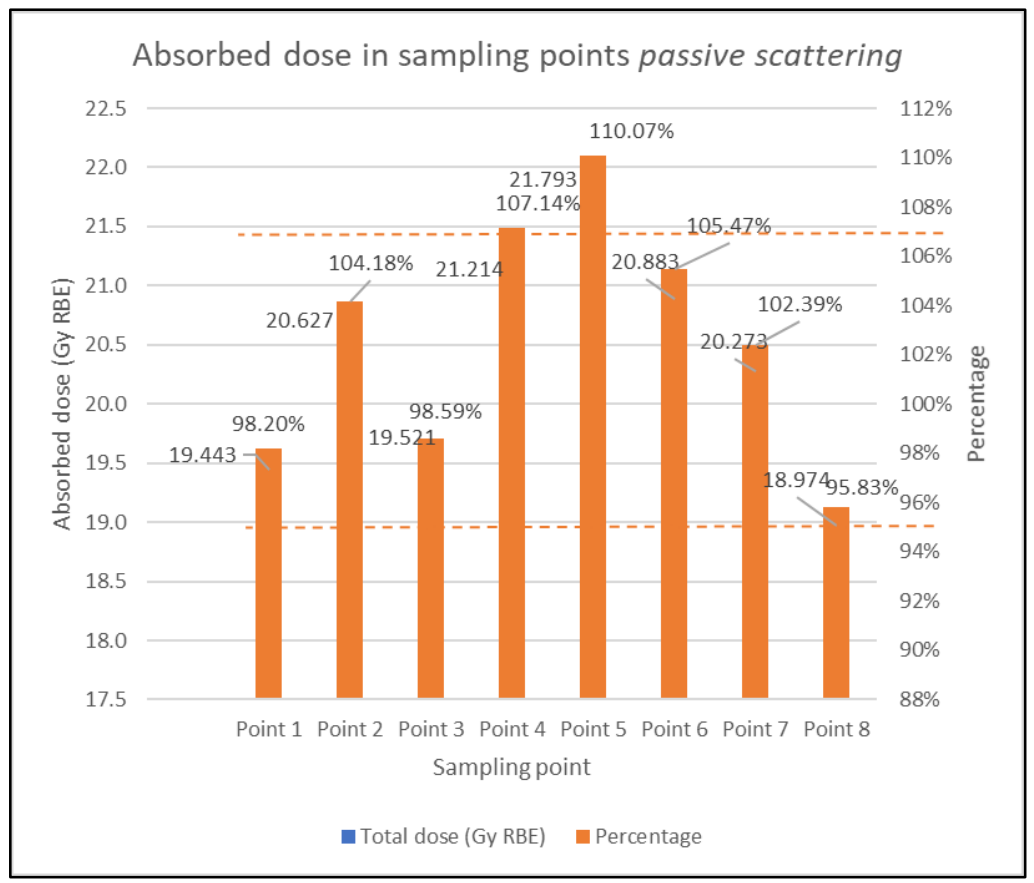

Fig. 9. Dose distribution passive scattering

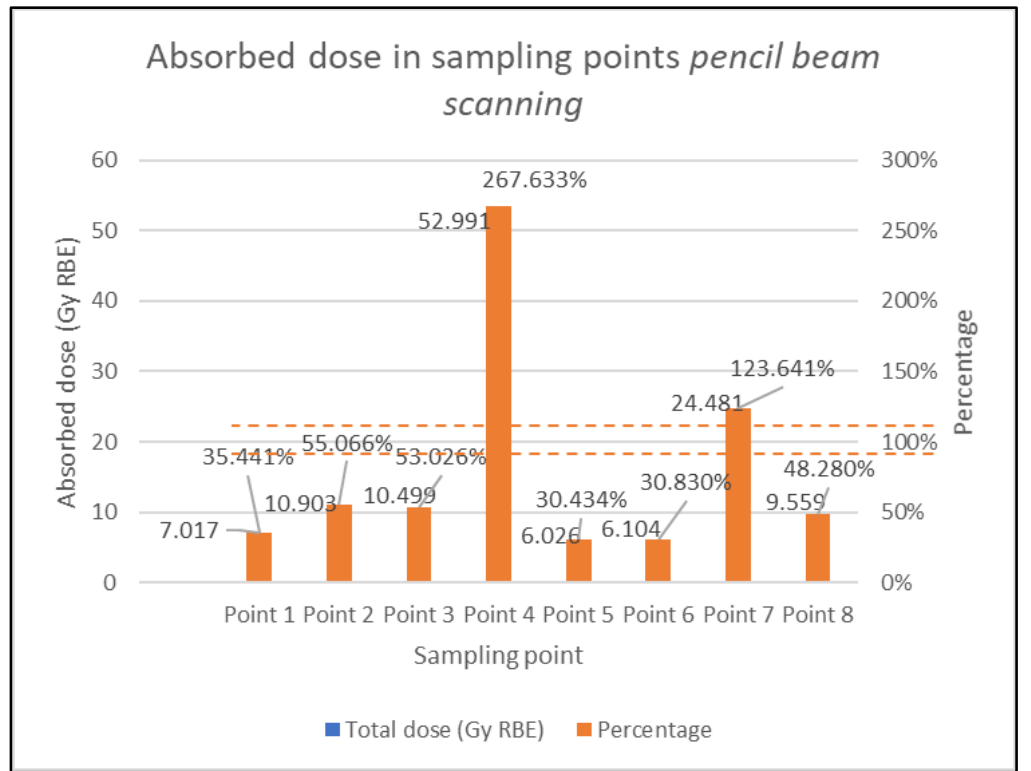

Fig. 10. Dose distribution in pencil beam scanning

Another consideration in planning radiotherapy is the absorbed dose distribution in the irradiation target volume. It is necessary to analyze the homogeneity of the dose received by PTV. The analysis was carried out by comparing the sampled dose at 8 points in the PTV area with the planned dose of 19.8 Gy RBE. The results of the dose distribution of the passive scattering technique are shown in Figure 9. From the figure, it can be seen that most of the sampling points have values that are still within the range of 95 to $107 \%$ of the planned dose. Two sampling points exceed the $107 \%$ dose, which is point 4 and points 5 . The presence of a point with a much higher dose than the planned dose is also called a hot spot. The hot spots at points 4 and 5 are due to their relative location in the middle of the PTV, so it could be seen that the proton beam dose distribution with this passive scattering technique is still not good, even though the overall area of PTV and CTV is still in the allowable dose range. For the pencil beam scanning technique, the radiation dose distribution received by the therapeutic target is shown in Figure 10. Contrary to the results obtained with the passive scattering technique, the distribution results in the pencil beam scanning technique are not homogeneous. None of the eight 
sampling points has a dose value of 95 to $107 \%$ of the planned dose. Of the 8 points, 6 points have values far below the $95 \%$ limit, ranging from 35 to $55 \%$, the so-called cold spots. Meanwhile, the two hot spots are point 4 and point 7 .

This inhomogeneous distribution was due to the use of proton beams with the pencil beam scanning technique in the form of $1 \mathrm{~cm}$ diameter beamlets formed in rows according to the PTV area. The formation of this row of beamlets formed a small gap between the beamlets, resulting in the inhomogeneity of the absorbed dose in PTV. So it could be concluded that the distribution of proton therapy doses with the pencil beam scanning technique in this study was still not acceptable, even though the overall doses for PTV and CTV already had values in an acceptable range. Compared with the passive scattering technique, the passive scattering technique had a relatively better absorption dose distribution with two hot spots than the pencil beam scanning technique with six cold spots and two hot spots.

The planned dose in radiotherapy cannot be delivered to the patient only in one fraction as it will cause a high toxicity effect. The planned dose in radiotherapy will be divided by fractionation to overcome this requisite. Various protocols can be used for fractionation schemes. One commonly used protocol is a maximum of $1.8 \mathrm{~Gy}$ RBE per fraction per day [20]. The whole posterior fossa boost scheme of $19.8 \mathrm{~Gy}$ RBE in cases of medulloblastoma cancer with proton therapy with 2 proton beam delivery techniques is shown in Table 5.

Table 5. Plan for fractionation

\begin{tabular}{cccccccc}
\hline No. & $\begin{array}{l}\text { Therapy } \\
\text { technique }\end{array}$ & $\begin{array}{c}\text { Beam } \\
\text { Intensity }\end{array}$ & $\begin{array}{c}\text { Reference } \\
\text { PTV } \\
\text { Dose }(G y \\
\text { RBE) }\end{array}$ & $\begin{array}{c}\text { Total PTV } \\
\text { dose (Gy } \\
\text { RBE) }\end{array}$ & $\begin{array}{c}\text { Percentage of PTV } \\
\text { Dosage to planning } \\
\text { dose }\end{array}$ & $\begin{array}{c}\text { Sessions } \\
\text { One-time } \\
\text { theconds) }\end{array}$ & $\begin{array}{c}\text { Total therapy } \\
\text { time (seconds) }\end{array}$ \\
\hline $\begin{array}{l}\text { Passive } \\
\text { Scattering }\end{array}$ & $1 \times 10^{10}$ & 19.8 & 19.7429 & $99.71 \%$ & 11 & 50 & 550 \\
$\begin{array}{l}\text { Pencil } \\
\text { Beam } \\
\text { Scanning }\end{array}$ & $1.5 \times 10^{8}$ & 19.8 & 19.7481 & $99.74 \%$ & 11 & 55 & 605 \\
\hline
\end{tabular}

\section{CONCLUSION}

The implementation of proton therapy for medulloblastoma cancer cases with the whole posterior fossa boost therapy scheme with passive scattering technique required 11 sessions with a total time of $550 \mathrm{~s}$, and the pencil beam scanning technique required 11 sessions for a total time of $605 \mathrm{~s}$. The OAR(s) with the most significant percentage of absorbed dose using passive scattering technique were skin, cranium, and muscle, i.e., $8.22 \pm 0.15 \%$, $5.51 \pm 0.05 \%$, and $1.39 \pm 0.04 \%$ compared to the maximum tolerated dose, while in the pencil beam scanning technique, the $\mathrm{OAR}(\mathrm{s})$ with the most significant percentage of absorbed dose were the skin, cranium and muscle, i.e., $5.42 \pm 0.8 \%, 4.43 \pm 0.05 \%$ and $0.51 \pm 0.05 \%$ of the maximum tolerated dose. Therefore, for both passive scattering and pencil beam scanning techniques, OAR(s) did not receive an absorbed dose that exceeds the maximum tolerated dose of each organ, and consequently still considered safe. Both techniques still have areas with various higher (hot spot) and lower (cold spot) doses than the planned dose.

\section{ACKNOWLEDGMENT}

This research was performed under collaboration by the Department of Nuclear Engineering and Engineering Physics, Faculty of Engineering, Universitas Gadjah Mada, Center for Accelerator Science and Technology, National Nuclear Energy Agency, and Nuclear Scientific Data Center and Nuclear Science and Technology Research Institute.

\section{AUTHOR CONTRIBUTION}

The main contributors to this article are Moh. Miftakhul Dwi Fianto, Yohannes Sardjono, Andang Widi Harto, Isman Mulyadi Triatmoko, Gede Sutresna Wijaya, and Yaser Kasesaz. All authors read and approved the final version of the manuscript. 


\section{REFERENCES}

1. Paganetti H., Proton Therapy Physics(Series in Medical Physics and Biomedical Engineering). 2012.[Online].Available: http://www.lavoisier. fr/livre/notice.asp?id=RK2W6SA2XKKOWQ.

2. Yeon Soo Yeom et al., Computation Speeds and Memory Requirements of Mesh-Type ICRP Reference Computational Phantoms in Geant4, MCNP6, and PHITS., Health Phys. 2019. 116(5):664-676.

3. Aksungur B., "Medulloblastoma: Diagnosis, Treatment, And Prognosis," Master's Thesis. 2016.

4. Aman R. A., et al., "Panduan Penatalaksanaan Tumor Otak," 2016. Available:http://kanker. kemkes.go.id/guidelines.php?id=5

5. BPJS Kesehatan, "Laporan Pengelolaan Program Tahun 2019 \& Laporan Keuangan Tahun 2019 (Auditan).” Badan Penyelenggara Jaminan Sosial Kesehatan, Jakarta Pusat.

6. Yeom Y. S., Han M. C., Kim C. H., Jeong J. H., Conversion of ICRP Male Reference Phantom to Polygon-surface Phantom. Phys Med Biol. 2013. 58(19):6985-7007.

7. Sanchez-Parcerisa D., and Udías J., "Teaching Treatment Planning for Protons with Educational Open-source Software: Experience with FoCa and MatRad," J. Appl. Clin. Med. Phys., 2018. 19 (4): 302-306.

8. Sato T. et al., "Features of Particle and Heavy Ion Transport code System (PHITS) version 3.02," J. Nucl. Sci. Technol., 2018. 55 (6):684690.

9. Carter L. M., Ocampo Ramos J. C., Kesner A. L., Personalized Dosimetry of $177 \mathrm{Lu}-$ DOTATATE: a Comparison of Organ- and Voxel-level Approaches using Open-access ImagesBiomed Phys Eng Express. 2021. 7(5): 34271565 .

10. Ute Linz and Jose Alonso., Laser-driven Ion Accelerators for Tumor Therapy Revisited. Phys. Rev. Accel. Beams., 2016. 19: 124802.

11. Yong Ho Chin, Alexander $\mathrm{Wu}$ Chao, and Michael M. Blaskiewicz, Two Particle Model for Studying the Effects of Space-Charge Force on Strong Head-tail Instabilities., Phys. Rev. Accel. Beams. 2016. 19: 014201.

12. Ostrom Q., T., et al., "CBTRUS Statistical Report: Primary Brain and Central Nervous System Tumors Diagnosed in the United States in 2007-2011," Neuro. Oncol., 2014. 16(4): iv1-iv63.

13. Ramaswamy V., et al., Medulloblastoma Subgroup-specific Outcomes in Irradiated Children: Who are the True High-risk
Patients?," Neuro. Oncol., 2016. 18(2) 291297.

14. Lukas M., C., et al., PARaDIM: A PHITSBased Monte Carlo Tool for Internal Dosimetry with Tetrahedral Mesh Computational Phantoms., J Nucl Med. 2019. 60(12): 18021811.

15. Cubillos-Mesías M., et al., "Impact of Robust Treatment Planning on Single- and Multi-Field Optimized Plans for Proton Beam Therapy of UnilateralHhead and Neck Target Volumes," Radiat. Oncol. 2017. 12(1)190-199.

16. Dörr W., T. Herrmann T., and Trott K., Normal Tissue Tolerance. 2017. 6 (5) 840-851.

17. Dionisi F., et al., "Organs at Risk's Tolerance and Dose Limits for Head and Neck Cancer Reirradiation: A literature Review," Oral Oncol., 2019. 98 (4)35-47.

18. Brodin P., and Wolfgang T. A., "Revisiting the Dose Constraints for Head and Neck OARs in the Current Era of IMRT," Oral Oncol., 2018. 18:8-18.

19. Tatsuhiko Sato et al.,Features of Particle and Heavy Ion Transport code System (PHITS) version 3.02, Journal of Nuclear Science and Technology. 2018. 55(6): 684-690.

20. Yock T., I., et al., "Long-term Toxic Effects of Proton Radiotherapy for Paediatric Medulloblastoma: A phase 2 Single-arm Study," Lancet Oncol. 2016. 17 (3):287-298. 
